\title{
Developing integrated remote sensing and GIS procedures for oil spill monitoring on the Libyan coast
}

\author{
A. Eljabri \& C. Gallagher \\ Department of Civil Engineering and Built Environment, \\ Glasgow Caledonian University, UK
}

\begin{abstract}
Remote sensing (RS) and geographic information systems (GIS) can contribute significantly to the correct interpretation of the slick signatures visible on satellite images. Initially, GIS has proven to be an excellent management tool for resource assessment, oil spill response and planning, and damage assessment. The approach to the problem of oil spill mapping includes integration of the geographical, remote sensing, oil and gas production/infrastructure data and slick signatures, detected by satellite images, in GIS. Compiled from data from several sources including nautical maps, geodatabases, ground truth and remote sensing data, GIS allows the retrieval of key information, such as predicting oil spill locations, revealing offshore/onshore sources, and estimating the intensity of oil pollution. Remote sensing and GIS technologies can improve the identification and classification of oil spills, leading to construction of the final product, an oil spill distribution map. This approach has been applied to oil spill mapping on the Libyan coast. We conclude that the combination of GIS and remote sensing RS technologies provides an ideal solution for understanding the spatial/temporal distribution of oil spills in the marine environment and is considered as the core of the oil spill monitoring system.
\end{abstract}

Keywords: remote sensing data, GIS, oil spills.

\section{Introduction}

The most recent statistics show that the variety of existing risks make part of the Libyan coast liable to oil pollution activity of different intensities [1]. In fact, Libyan coastal areas are already exposed to marine pollution and to all the 
disasters generating from it. The frequencies of the pollution often provoke severe damage to the coastal environment. Remote Sensing and GIS can be very useful tools to complement the methods used in disaster management mitigation of disaster of oil spills management. However, it should be observed that their achievements depend on the level of knowledge obtained about the expected frequency, character, and magnitude of hazard events in an area [2]. Remote sensing also allows the monitoring of the event as it occurs. From the vantage point of satellite, it is possible to consider, plan for and operationally monitor the event.

This paper discusses the working process for the development of an oil spill management system at a Libyan coastal area, through the use of GIS and remote sensing technologies. Such devices are expected to provide a real time and low cost system for detecting oil spill, and monitor oil spills along the Libyan coast.

Practically, the system consists of three sub-systems; the detection and monitoring, then the spatial database and finally the prediction.

Hence, GIS is a useful tool of oil spill management if it is used effectively and efficiently.

\section{Methodology}

\subsection{Data availability and acquisition}

Developing Integrated Remote Sensing and GIS procedures for oil spills will be conducted through the use of the primary data available as regards to the historical elements of oil spills obtained from the Department of Environment (DOE) and other important sources such as shoreline natural resources, coastal land use, and so on which were collected from documented papers and related Surveying Department of Libya (SDL) and with Libyan remote sensing (LRS) which provided colour aerial photography of the site from 2000 to 2010 and $5 \mathrm{~m}$ resolution Compact Airborne Spectrographic Imager image with intertidal zone classification, corrected image, and a land cover map of the Libyan coast with $5 \mathrm{~m}, 25 \mathrm{~m}$ resolution land cover grid and so on. Remotely sensed data was primarily processed using EARDASImage and ArcGIS then exported to the database for modeling. For the first risk of oil pollution, we present, in this paper, a methodology developed for oil spill identification.

\subsection{Geographical information system}

Physical maps of the Libyan coast with a scale of 1:50,000 will be used as a base map for the thematic layer and registration of each processed image. Spatial and non-spatial data will be analysed through various functions of GIS techniques, such as vectorization, rasterization, data analysis and overlaying, and modeling to yield an oil spill management system such as thematic layers (map composition). 


\subsection{Spill trajectory model}

A simple linear oil spill trajectory model developed and will be customised into the GIS environment. The velocity and direction of winds and currents are the parameters. An oil slick is always under influence of both parameters; hence the present drift prediction is based on these combined effects.

$$
\text { Oil slick movement }=\mathrm{Cw}(\mathrm{z}) . \mathrm{Uw}+\mathrm{ca}(\mathrm{z}) . \mathrm{Ua}
$$

where $\mathrm{Cw}$ is wind drift factor, $\mathrm{Uw}$ is wind velocity at $10 \mathrm{~m}$ above the water surface, ca is current drift factor, and Ua is depth average current velocity.

\section{Coastal pollution}

The problem of the marine coastal pollution is probably one of the most worrying aspects of environmental deterioration. Among the remote sensing technologies, SAR (Synthetic Aperture Radar) is very promising because it can provide images both night and day, even when it is cloudy. The visual effect of an oil slick on a SAR image is a dark area [2]. There are a certain number of image features that can be considered as slick signatures, according to Litovchenko et al. [3]. Physical and geometric parameters alone are not always sufficient to provide enough information in order to identify the nature of the oil spill [4]. There are several natural phenomena that can have the same radar signature as an oil spill. To help in the identification of the suspect objects, supplementary data, such as the wind speed that can be calculated from radar images, have proved to be efficient [5]. For instance, it has been observed that, when the wind speed is over $7-8 \mathrm{~m} / \mathrm{s}$ and under $15 \mathrm{~m} / \mathrm{s}$, the probability that the slick is an oil spill increases significantly because all other types of spills tend to disappear in the meantime. When the wind speed is under. $<3 \mathrm{~m} / \mathrm{s}$ ) [6], the slick may also be caused by natural phenomena (Brekke and Solbergel [1]). Integrated with the tool for the estimation of the wind vector, and oil spill scheme (represented in Figure 1), the method for oil spill identification can be described by the following procedures shown in the figure below.

\section{The result}

Analysis of oil spills is a complex task, as many factors can play important roles in the occurrence of the disastrous events. Therefore, any type of analysis requires a large number of input parameters, and needs a tool able to store and display all information related to the target area. The proper structure of information system for disaster of oil spills management should be present to tackle the disaster and to manage it. In this research, we presented our contribution of Libyan experience in the use of space technologies for oil spills management. Specifically, GIS is presented as an interesting instrument to integrate territorial data, making tasks such as variable analysis easier, its inclusion in a predictive model, and future scene simulations where remote 


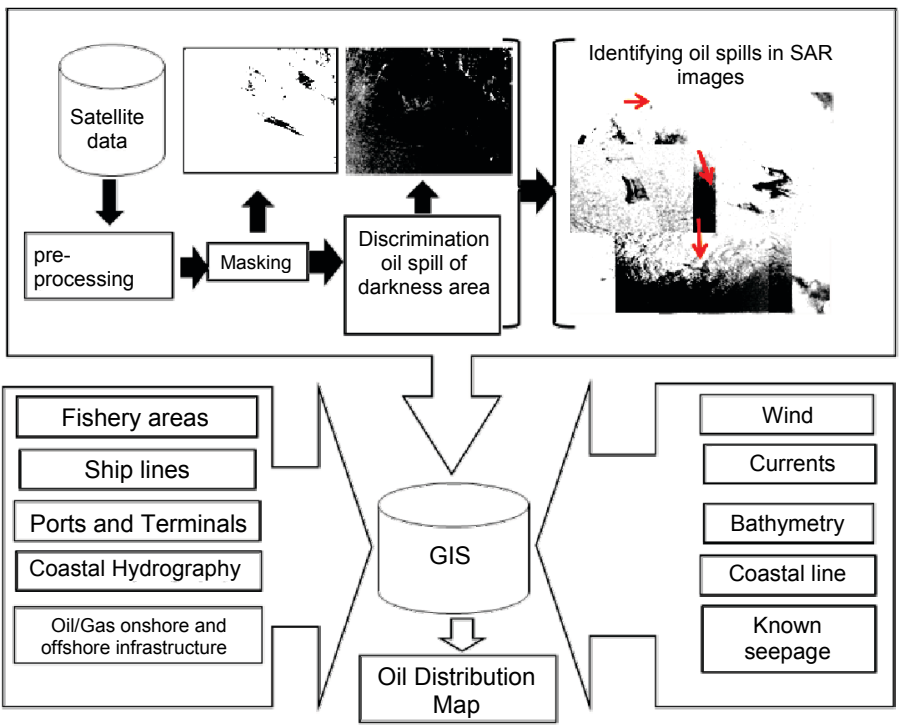

Figure 1: Diagram of paper methodology. Oil spill maps will indicate the marine coastal areas that are exposed to oil pollution.

sensing and GIS can provide useful information, and generate the awareness about the dire consequences of spills among politicians, influential decisionmakers, and the general public. This might result with the setting up of disaster management organisations. Oil spill maps will clearly indicate those marine areas exposed to oil pollution and will identify pollutants and oil pollution spreading and accumulation areas are shown in Figure 2 by the colour red.

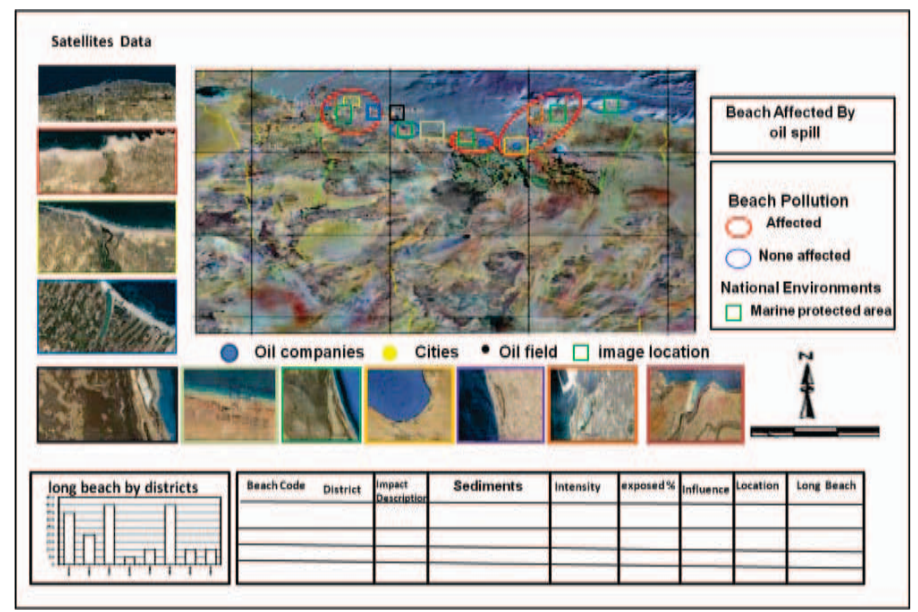

Figure 2: $\quad$ Satellite image generated with GIS and remote sensing data for oil spill management on the Libyan coast. 


\section{Conclusion}

Remote sensing RS and GIS have proven to be an excellent management tool for resource assessment, oil spill response and planning, and damage assessment. The GIS approach to the problem of oil spill mapping includes integration of the geographical, remote sensing, oil and gas production/infrastructure data and slick signatures, detected by satellite images, in GIS. Compiled from data from several sources including nautical maps, geodatabases, ground truth and remote sensing data, GIS allows the retrieval of key information, such as predicting oil spill locations, revealing offshore/onshore sources, and estimating the intensity of oil pollution. Remote sensing (RS) and GIS technologies can improve the identification remote sensing (RS) and geographic information system (GIS) can and classification of oil spills, leading to construction of the final product, an oil spill distribution map. This approach to be applied to oil spill mapping in the Libyan sea.

\section{References}

[1] Brekke, C. and Solberg, A. H. S. (2005). Oil spill detection by satellite remote sensing, Rem. Sens. Environ., 95, 1-13.

[2] Klemas, V. 2010. Tracking oil slicks and predicting their trajectories using remote sensors and models: case studies of the Sea Princess and Deepwater Horizon oil spills. Journal of Coastal Research, 26(5), 789-797. West Palm Beach (Florida), ISSN 0749-0208

[3] Litovchenko, K. T., Lavrova, O. Y., Mityagina, M. I., Ivanov, A. Y. and Yurenko, Y. I. 2007. Oil pollution in the Eastern Black Sea: Monitoring from space and sub-satellite verification. Issledovanie Zemli iz Kosmosa, 1, 81-94.

[4] Shaw, P. J., Walda, Walid, Hawkins, J. (2010), (Coastal oil pollution Libya I: hydrocarbone in surface seawater and marine sediments

[5] Topouzelis, K., Bernardini, A., Ferraro, G., Meyer-Roux, S. and Tarchi, D. (2006). Satellite mapping of oil spills in the Mediterranean Sea, Fresenius Environmental Bulletin, 15, 1009-1014.

[6] Topouzelis, K., Karathanassi, V., Pavlakis, P. and Rokos, D. (2007). Detection and discrimination between oil spills and look-alike phenomenon through neural networks. Journal of Photogrammetry \& Remote Sensing, 62, 264-270. 